\title{
New onset and persistent symptoms of post-traumatic stress disorder self reported after deployment and combat exposures: prospective population based US military cohort study
}

\author{
Tyler C Smith, director , 1,2 Margaret A K Ryan, associate adjunct professor, ${ }^{1,2}$ Deborah L Wingard, professor \\ and associate chief, ${ }^{2}$ Donald I Slymen, professor, ${ }^{3}$ James F Sallis, professor, , ${ }^{4}$ Donna Kritz-Silverstein, \\ professor ${ }^{5}$ for the Millennium Cohort Study Team
}

\section{${ }^{1}$ Department of Defense Center for Deployment Health Research at the Naval Health Research Center, San Diego, CA 92106, USA \\ ${ }^{2}$ Division of Epidemiology, Department of Family and Preventive Medicine, University of California San Diego, La Jolla, CA 92093-0607 \\ ${ }^{3}$ Graduate School of Public Health, San Diego State University, San Diego, CA 92108 \\ ${ }^{4}$ Department of Psychology, San Diego State University, San Diego, CA 92108 \\ ${ }^{5}$ Division of Epidemiology, Department of Family and Preventive Medicine, University of California San Diego, La Jolla, CA 92093-0631 \\ Correspondence to: T C Smith} tyler.c.smith@med.navy.mil

\section{ABSTRACT}

Objective To describe new onset and persistence of self reported post-traumatic stress disorder symptoms in a large population based military cohort, many of whom were deployed in support of the wars in Iraq and Afghanistan.

Design Prospective cohort analysis.

Setting and participants Survey enrolment data from the millennium cohort (July 2001 to June 2003) obtained before the wars in Iraq and Afghanistan. Follow-up (June 2004 to February 2006) data on health outcomes collected from 50184 participants.

Main outcome measures Self reported post-traumatic stress disorder as measured by the posttraumatic stress disorder checklist-civilian version using Diagnostic and Statistical Manual of Mental Disorders, fourth edition criteria.

Results More than $40 \%$ of the cohort were deployed between 2001 and 2006; between baseline and followup, $24 \%$ deployed for the first time in support of the wars in Iraq and Afghanistan. New incidence rates of 10-13 cases of post-traumatic stress disorder per 1000 person years occurred in the millennium cohort. New onset self reported post-traumatic stress disorder symptoms or diagnosis were identified in $7.6-8.7 \%$ of deployers who reported combat exposures, $1.4-2.1 \%$ of deployers who did not report combat exposures, and $2.3-3.0 \%$ of nondeployers. Among those with self reported symptoms of post-traumatic stress disorder at baseline, deployment did not affect persistence of symptoms.

Conclusions After adjustment for baseline characteristics, these prospective data indicate a threefold increase in new onset self reported post-traumatic stress disorder symptoms or diagnosis among deployed military personnel who reported combat exposures. The findings define the importance of post-traumatic stress disorder in this population and emphasise that specific combat exposures, rather than deployment itself, significantly affect the onset of symptoms of post-traumatic stress disorder after deployment.

\section{INTRODUCTION}

For more than five years the US military has been engaged in a combat intensive deployment in Iraq, Afghanistan, and neighbouring countries. Concern is growing among the public and veterans that postdeployment health consequences among US military personnel may be considerable and lasting. A recent report suggested that US marine and army infantry units returning from duty in Iraq and Afghanistan have higher than expected proportions of mental disorders and that as many as $10 \%$ of personnel are returning home with symptoms of post-traumatic stress disorder. ${ }^{1}$ Combat duty in Iraq has been associated with high use of mental health services and attrition from military service and possible alterations in neural functioning after deployment. ${ }^{23}$

Symptoms of post-traumatic stress disorder have been reported in as many as 30\% of veterans after service in Vietnam and in more than $10 \%$ of US military personnel returning from the 1991 Gulf war. ${ }^{12-9}$ Epidemiological studies to date have largely focused on retrospective data or select groups. Prospective investigation of the causes of the disorder in large, population based military cohorts has been limited. The objective of this study was to prospectively investigate the effect of military deployment and self reported exposure to combat on new onset and persistent symptoms of post-traumatic stress disorder in a large population based US military cohort. The unique nature of the millennium cohort study allows the investigation of both personnel on active duty and Reserve/National Guard members who have remained in military service or who have separated from the military after returning from deployment.

\section{METHODS}

\section{Study population}

Between July 2001 and June 2003 the first panel of participants in the millennium cohort study, a population based US military cohort of 77047 active military 
duty and Reserve/National Guard personnel, was enrolled in a 22 year longitudinal study of health. ${ }^{10}$ The baseline enrolment ended with $36 \%$ of personnel invited consenting to participate in the 21 year study. Analyses to investigate potential reporting biases show no differences in responders' health with respect to hospital admissions and outpatient encounters in the year before enrolment (data not yet published); strong test-retest reliability ${ }^{11}$; reliable vaccination reporting, ${ }^{12}{ }^{13}$ occupation reporting, ${ }^{14}$ and deployment reporting ${ }^{15}$; and minimal differences between participants who chose web submission and those who chose paper submission. ${ }^{16}$ Between June 2004 and February 2006, $55021(71 \%)$ cohort members participated in the first three year follow-up questionnaire. Analyses of potential responder bias to the initial follow-up are ongoing.

To prospectively investigate new onset self reported symptoms of post-traumatic stress disorder, we removed participants deployed in support of the wars in Iraq and Afghanistan before their submission of the baseline questionnaire $(n=2230)$ and those who were deployed while submitting the baseline questionnaire $(\mathrm{n}=621)$ from these analyses. Among those deployed, we removed participants who submitted their follow up questionnaires during their first deployment $(\mathrm{n}=1986)$, leaving 50184 participants for these analyses.

We linked demographic and military personnel data to each participant; these reflected status at the time of baseline enrolment. These data included sex, birth year (categorised by groups: pre-1960, 1960-9, 1970-9, and 1980 forward), level of education (high school or less, some college or bachelor's degree, advanced degree), marital status (married, never married, divorced/ other), pay grade (enlisted or officer), race/ethnicity (white non-Hispanic, black non-Hispanic, and other), service component (active duty or Reserve/National Guard), service branch (army, air force, navy/Coast Guard, or marines), and occupation (combat specialists, healthcare specialists, service supply and functional support specialists, or other). We used self reported data to supplement missing data from personnel records as needed.

\section{Deployment data}

We categorised regular active duty and Reserve/ National Guard personnel who had been deployed

Table 1|Baseline demographic and behavioural characteristics by deployment status of 50128 millennium cohort members. Values are numbers (percentages)

Characteristic*

Deployed $†$ ( $n=11$ 952)

Non-deployed $\dagger(n=38$ 176)

Sex

\begin{tabular}{|c|c|c|}
\hline Male & $9727(81.4)$ & $26552(69.6)$ \\
\hline Female & $2225(18.6)$ & $11624(30.4)$ \\
\hline \multicolumn{3}{|l|}{ Birth year } \\
\hline Pre-1960 & $2078(17.4)$ & $10714(28.1)$ \\
\hline $1960-9$ & $4943(41.4)$ & $15362(40.2)$ \\
\hline 1970-9 & $4286(35.9)$ & $10728(28.1)$ \\
\hline 1980 and forward & $645(5.4)$ & $1372(3.6)$ \\
\hline \multicolumn{3}{|l|}{ Education } \\
\hline High school or less diploma/equivalent & $5241(43.9)$ & $16452(43.1)$ \\
\hline Some college or bachelor's degree & $5736(48.0)$ & $17003(44.5)$ \\
\hline Advanced degree & $975(8.1)$ & $4721(12.4)$ \\
\hline \multicolumn{3}{|l|}{ Marital status } \\
\hline Married & $7784(65.1)$ & $25667(67.2)$ \\
\hline Never married & $3406(28.5)$ & $9615(25.2)$ \\
\hline Divorced & $762(6.4)$ & $2894(7.6)$ \\
\hline \multicolumn{3}{|l|}{ Race/ethnicity } \\
\hline White non-Hispanic & $8443(70.6)$ & $27123(71.1)$ \\
\hline Black non-Hispanic & $1312(11.0)$ & $4834(12.7)$ \\
\hline Other & $2197(18.4)$ & 6219 (16.3) \\
\hline \multicolumn{3}{|l|}{ Smoking } \\
\hline Never smoker & $7126(59.6)$ & $22816(59.8)$ \\
\hline Past smoker & 2855 (23.9) & $9768(25.6)$ \\
\hline Current smoker & $1971(16.5)$ & $5592(14.7)$ \\
\hline \multicolumn{3}{|l|}{ Problem drinking } \\
\hline No & 9723 (81.4) & 31327 (82.1) \\
\hline Yes & 2229 (18.6) & 6849 (17.9) \\
\hline
\end{tabular}

*Taken at time of submission of baseline questionnaire among members who submitted questionnaires at baseline (July 2001-June 2003) and followup (July 2004-Jan 2006).

tDeployment in support of wars in Iraq and Afghanistan considered if full deployment occurred between submission dates of baseline and follow-up questionnaires. Cohort members who were deployed after follow-up survey are included with non-deployers in these analyses. 
for one or more days in support of the wars in Iraq and Afghanistan between submission of their baseline and follow-up questionnaires as deployers. We categorised cohort members who had never been deployed or who were deployed for the first time after submission of their baseline and follow-up questionnaires as nondeployers in these analyses. The Defense Manpower Data Center, Monterey Bay, CA, provided deployment data, including entry and exit deployment dates. These data correlate strongly with millennium cohort self reported deployment status. ${ }^{15}$

Post-traumatic stress disorder assessment

Because of the complexity of diagnosing post-traumatic stress disorder and the differences in reported prevalence estimates, ${ }^{5}$ we used the standardised posttraumatic stress disorder checklist-civilian version, with highly sensitive and specific criteria for symptoms of post-traumatic stress disorder. The sensitive definition of symptoms of post-traumatic stress disorder used the Diagnostic and Statistical Manual of Mental Disorders, fourth edition (DSM-IV) criteria alone, whereas the specific definition of symptoms of post-traumatic stress disorder included the DSM-IV criteria and a requirement for a sum of 50 on a scale from 17 to 85 points for all of the questions in the checklist. ${ }^{17-21}$ The posttraumatic stress disorder checklist—civilian version is a 17 item self report measure of symptoms of post-traumatic stress disorder that requires participants to rate the severity of each symptom during the previous 30 days on a Likert-type scale ranging from 1 (not at all) to 5 (extremely). The DSM-IV criteria for post-traumatic stress disorder were met when a participant reported a moderate or higher level of at least one intrusion symptom, three avoidance symptoms, and two hyperarousal symptoms. ${ }^{18}$ The DSM-IV criteria alone are reported to have a $100 \%$ sensitivity with a specificity of $92.0 \%$, and the stricter criteria of at least 50 points on the checklist have shown reasonable sensitivity $(0.60)$ and high specificity (0.99). ${ }^{17}$ The internal consistency of the standardised checklist in the millennium cohort, as measured by Cronbach's $\alpha(\alpha=0.94)$, indicated that these data were internally reliable for this population. ${ }^{11}$

In addition to the assessment of self reported posttraumatic stress disorder symptoms at baseline with standard instruments, we asked participants, "Has your doctor or other health professional ever told you that you have any of the following conditions? . . . Posttraumatic stress disorder." In the follow-up questionnaire, we replaced "ever" with "in the past three years," which was used to indicate a more recent diagnosis.

We identified participants as having new onset self reported symptoms of post-traumatic stress disorder if they did not have symptoms or diagnosis at baseline but at follow-up met the criteria for the standardised checklist or reported a diagnosis by a healthcare worker of post-traumatic stress disorder within the previous three years. We identified participants as having persistent self reported symptoms of posttraumatic stress disorder if they were identified as having symptoms at baseline and at follow-up.

\section{Other questionnaire information}

We assessed cigarette smoking (never smoker, past smoker, current smoker) by using responses to the following questions: "In your lifetime, have you smoked at least 100 cigarettes (five packs)?", "In the past year have you used cigarettes?", and "Have you ever tried to quit smoking?" We assessed problem alcohol drinking (yes/no) with a standardised questionnaire. $^{22}$

Table 2 | Baseline military and occupational characteristics by deployment status, of 50128 millennium cohort members. Values are numbers (percentages)

\begin{tabular}{|c|c|c|}
\hline Characteristic* & Deployed $+(n=11$ 952) & Non-deployed $+(n=38$ 176) \\
\hline \multicolumn{3}{|l|}{ Military rank } \\
\hline Enlisted & $8802(73.6)$ & $27556(72.2)$ \\
\hline Officer & $3150(26.4)$ & $10620(27.8)$ \\
\hline \multicolumn{3}{|l|}{ Service component } \\
\hline Reserve/National Guard & $4543(38.0)$ & $17988(47.1)$ \\
\hline Active duty & $7409(62.0)$ & $20188(52.9)$ \\
\hline \multicolumn{3}{|l|}{ Branch of service } \\
\hline Army & $5548(46.4)$ & $18438(48.3)$ \\
\hline Air force & $4333(36.3)$ & $10608(27.8)$ \\
\hline Navy/Coast Guard & $1478(12.4)$ & 7582 (19.9) \\
\hline Marine Corps & $593(5.0)$ & $1548(4.1)$ \\
\hline \multicolumn{3}{|l|}{ Occupational category } \\
\hline Other occupations & $5185(43.4)$ & $14341(37.6)$ \\
\hline Combat specialists & $2901(24.3)$ & $7114(18.6)$ \\
\hline Healthcare specialists & $864(7.2)$ & $5005(13.1)$ \\
\hline Service supply and functional & $3002(25.1)$ & $11716(30.7)$ \\
\hline \multicolumn{3}{|c|}{$\begin{array}{l}\text { *Taken at time of submission of baseline questionnaire among members who submitted questionnaires at baseline (July 2001-June 2003) and follow- } \\
\text { up (July 2004-Jan 2006). } \\
\text { †Deployment in support of wars in Iraq and Afghanistan considered if full deployment occurred between submission dates of baseline and follow-up } \\
\text { questionnaires. Cohort members who were deployed after follow-up survey are included with non-deployers in these analyses. }\end{array}$} \\
\hline
\end{tabular}


To assess combat exposures, the follow-up survey asked: "During the past three years, have you been personally exposed to any of the following?" Answer options were "Witnessing a person's death due to war, disaster, or tragic event," "Witnessing instances of physical abuse (torture, beating, rape)," "Dead and/or decomposing bodies," "Maimed soldiers or civilians," and "Prisoners of war or refugees." We combined these with deployment experience to indicate a deployment with self reported stressful or combat exposures.

\section{Statistical analysis}

We completed descriptive and univariate analyses of population characteristics by deployment status and new onset and persistent self reported symptoms or diagnosis of post-traumatic stress disorder. We grouped deployment status as no deployment between baseline and follow-up questionnaires, deployment without self reported combat exposures between submission of baseline and follow-up questionnaires, and deployment in support of the wars in Iraq and Afghanistan with self reported combat exposures between submission of baseline and follow-up questionnaires.

We used multivariable logistic regression to compare the adjusted odds of association between deployment in support of the wars in Iraq and Afghanistan and new onset self reported symptoms or diagnosis of posttraumatic stress disorder. We did secondary analyses of self reported persistence of post-traumatic stress disorder on a subpopulation of participants with symptoms at baseline. We used SAS software, version 9.1.3, for data management and statistical analyses.

\section{RESULTS}

Data were complete and available for these analyses for $50128(99.9 \%)$ of the 50184 eligible cohort members. The mean elapsed time between baseline and

Table 3 |New onset and persistent self reported symptoms of post-traumatic stress disorder by demographic and behavioural characteristics of millennium cohort members. Values are numbers (percentages)

\begin{tabular}{|c|c|c|c|c|}
\hline \multirow[b]{2}{*}{ Characteristic* } & \multicolumn{2}{|c|}{$\begin{array}{l}\text { No post-traumatic stress disorder } \\
\text { symptoms or diagnosis at baseline }\end{array}$} & \multicolumn{2}{|c|}{$\begin{array}{l}\text { Post-traumatic stress disorder symptoms at } \\
\text { baseline }\end{array}$} \\
\hline & $\begin{array}{l}\text { New onset symptoms } \\
\text { by specific criteria† } \\
(1347 / 48 \text { 447) }\end{array}$ & $\begin{array}{c}\text { New onset symptoms } \\
\text { by sensitive criteriaf } \\
(1695 / 47837)\end{array}$ & $\begin{array}{c}\text { Persisting symptoms } \\
\text { by specific criteria } \dagger \\
(455 / 995)\end{array}$ & $\begin{array}{c}\text { Persisting symptoms } \\
\text { by sensitive criteriaf } \\
\quad(733 / 1659)\end{array}$ \\
\hline \multicolumn{5}{|l|}{ Sex } \\
\hline Male & $851(2.4)$ & $1084(3.1)$ & $296(45.8)$ & $482(43.5)$ \\
\hline Female & $496(3.8)$ & $611(4.7)$ & $159(45.7)$ & $251(45.6)$ \\
\hline \multicolumn{5}{|l|}{ Birth year } \\
\hline Pre-1960 & $276(2.2)$ & $343(2.8)$ & $137(57.8)$ & $191(50.7)$ \\
\hline 1960-9 & $456(2.3)$ & $594(3.1)$ & $150(45.7)$ & $248(44.1)$ \\
\hline $1970-9$ & $512(3.5)$ & $627(4.4)$ & $138(39.2)$ & $237(40.2)$ \\
\hline 1980 and forward & $103(5.4)$ & $131(7.0)$ & $30(38.5)$ & $57(43.5)$ \\
\hline \multicolumn{5}{|l|}{ Education } \\
\hline $\begin{array}{l}\text { High school or less diploma/ } \\
\text { equivalent }\end{array}$ & $859(4.2)$ & $1041(5.1)$ & $264(42.7)$ & $458(43.5)$ \\
\hline Some college or bachelor's degree & $416(1.9)$ & $568(2.6)$ & $166(49.4)$ & $241(44.2)$ \\
\hline Advanced degree & $72(1.3)$ & $86(1.5)$ & $25(62.5)$ & $34(54.8)$ \\
\hline \multicolumn{5}{|l|}{ Marital status } \\
\hline Married & $790(2.4)$ & $1000(3.1)$ & $261(46.4)$ & $421(43.8)$ \\
\hline Never married & $420(3.4)$ & $532(4.3)$ & $141(43.3)$ & $233(44.1)$ \\
\hline Divorced & $137(3.9)$ & $163(4.8)$ & $53(50.0)$ & $79(46.8)$ \\
\hline \multicolumn{5}{|l|}{ Race/ethnicity } \\
\hline White non-Hispanic & $889(2.6)$ & $1134(3.3)$ & $310(46.6)$ & $505(44.1)$ \\
\hline Black non-Hispanic & $207(3.5)$ & $247(4.2)$ & $73(47.4)$ & $112(46.5)$ \\
\hline Other & $251(3.1)$ & 314 (3.9) & $72(40.9)$ & $116(42.3)$ \\
\hline \multicolumn{5}{|l|}{ Smoking at baseline } \\
\hline Never smoker & $654(2.2)$ & $831(2.9)$ & $185(43.7)$ & 294 (41.6) \\
\hline Past smoker & $356(2.9)$ & $463(3.9)$ & $136(46.0)$ & $220(45.5)$ \\
\hline Current smoker & $337(4.7)$ & $401(5.8)$ & $134(48.6)$ & $219(46.7)$ \\
\hline \multicolumn{5}{|l|}{ Problem drinking at baseline } \\
\hline No & $1008(2.5)$ & $1278(3.2)$ & $289(45.0)$ & $459(42.3)$ \\
\hline Yes & $339(4.0)$ & $417(5.0)$ & $166(47.0)$ & $274(47.7)$ \\
\hline \multicolumn{5}{|c|}{$\begin{array}{l}\text { *Taken at time of baseline submission of questionnaire among members who submitted questionnaires at baseline (July 2001-June 2003) and follow- } \\
\text { up (July 2004-Jan 2006). } \\
\text { †Self reported post-traumatic stress disorder symptoms based on posttraumatic stress disorder patient checklist-civilian version with DSM-IV criteria } \\
\text { or diagnosis of post-traumatic stress disorder within previous three years. } \\
\ddagger \text { felf reported post-traumatic stress disorder symptoms based on posttraumatic stress disorder patient checklist-civilian version with DSM-IV criteria } \\
\text { and a sum of } 50 \text { points out of } 85 \text { points possible or diagnosis of post-traumatic stress disorder within previous three years. }\end{array}$} \\
\hline
\end{tabular}


submission of follow-up questionnaire was 2.7 years (SD 0.5 years; median 2.8 years). Deployed cohort members were proportionately more likely than nondeployed cohort members to be male, born between 1970 and 1979, less educated, on active duty, and combat specialists (table 1 and table 2).

When we applied the specific criteria for posttraumatic stress disorder, 1681 participants had self reported symptoms of post-traumatic stress disorder or a previous diagnosis at baseline. When we applied the sensitive criteria for post-traumatic stress disorder, 2291 participants had self reported symptoms of posttraumatic stress disorder or a previous diagnosis at baseline. This left 48447 or 47837 cohort members respectively available for analyses of new onset self reported symptoms or diagnosis of post-traumatic stress disorder (table 3, table 4).

Tables 3 and 4 present analyses of new onset self reported symptoms or diagnosis of post-traumatic stress disorder. We found new onset symptoms defined by the specific criteria of DSM-IV with a sum of 50 points on the checklist in $4.3 \%$ of deployed cohort members and $2.3 \%$ of non-deployed cohort members.
We found new onset symptoms defined by the specific criteria of DSM-IV with a sum of 50 points on the checklist in $7.6 \%$ of cohort members who were deployed and self reported combat exposures, 1.4\% of cohort members who were deployed and did not self report combat exposures, and 2.3\% of non-deployed cohort members. Applying the more sensitive DSMIV criteria alone, we identified new onset self reported symptoms of post-traumatic stress disorder in $8.7 \%$, $2.1 \%$, and $3.0 \%$ of these categories of cohort members. These data correspond to new onset self reported symptoms or diagnosis of post-traumatic stress disorder in up to 21 per 1000 non-combat deployers and up to 87 per 1000 combat deployed military personnel. New onset self reported symptoms of post-traumatic stress disorder were proportionately higher among cohort members who were female, younger, high school or less educated, never married or divorced, black non-Hispanic, enlisted, Reserve/National Guard members, army personnel, healthcare specialists, and service supply and functional specialists, and in those who self reported being a current smoker or problem drinker at baseline.

Table $4 \mid$ New onset and persistent self reported post-traumatic stress disorder symptoms by military and occupational characteristics of millennium cohort members. Values are numbers (percentages)

\begin{tabular}{|c|c|c|c|c|}
\hline \multirow[b]{2}{*}{ Characteristic* } & \multicolumn{2}{|c|}{$\begin{array}{l}\text { No post-traumatic stress disorder } \\
\text { symptoms or diagnosis at baseline }\end{array}$} & \multicolumn{2}{|c|}{$\begin{array}{l}\text { Post-traumatic stress disorder symptoms at } \\
\text { baseline }\end{array}$} \\
\hline & $\begin{array}{c}\text { New onset symptoms } \\
\text { by specific criteria } † \\
(1347 / 48447)\end{array}$ & $\begin{array}{c}\text { New onset symptoms } \\
\text { by sensitive criteriaf } \\
(1695 / 47837)\end{array}$ & $\begin{array}{c}\text { Persisting symptoms } \\
\text { by specific criteria† } \\
(455 / 995)\end{array}$ & $\begin{array}{c}\text { Persisting symptoms } \\
\text { by sensitive criteriaf } \\
(733 / 1659)\end{array}$ \\
\hline \multicolumn{5}{|l|}{ Deployment§ } \\
\hline Not deployed & 849 (2.3) & $1106(3.0)$ & $391(47.6)$ & $614(45.9)$ \\
\hline $\begin{array}{l}\text { Deployed without combat } \\
\text { exposures }\end{array}$ & $89(1.4)$ & $128(2.1)$ & $17(26.2)$ & $30(22.4)$ \\
\hline $\begin{array}{l}\text { Deployed with combat } \\
\text { exposures }\end{array}$ & $409(7.6)$ & $461(8.7)$ & $47(43.5)$ & $89(47.9)$ \\
\hline \multicolumn{5}{|l|}{ Military rank } \\
\hline Enlisted & $1162(3.3)$ & $1451(4.2)$ & $403(45.0)$ & $656(43.9)$ \\
\hline Officer & $185(1.4)$ & $244(1.8)$ & $52(52.0)$ & $77(46.4)$ \\
\hline \multicolumn{5}{|l|}{ Service component } \\
\hline Reserve/National Guard & $630(2.9)$ & $784(3.7)$ & $218(49.1)$ & $338(45.6)$ \\
\hline Active duty & $717(2.7)$ & $911(3.5)$ & $237(43.0)$ & $395(43.1)$ \\
\hline \multicolumn{5}{|l|}{ Branch of service } \\
\hline Army & 906 (3.9) & $1103(4.9)$ & $280(45.0)$ & $459(45.8)$ \\
\hline Air force & $184(1.3)$ & $267(1.8)$ & $82(48.0)$ & $114(37.9)$ \\
\hline Navy/Coast Guard & $195(2.2)$ & $250(2.9)$ & $67(42.7)$ & $118(42.6)$ \\
\hline Marine Corps & $62(3.0)$ & $75(3.7)$ & $26(57.8)$ & $42(53.2)$ \\
\hline \multicolumn{5}{|l|}{ Occupational category } \\
\hline Other occupations & $517(2.7)$ & $683(3.7)$ & $175(42.8)$ & $288(42.4)$ \\
\hline Combat specialists & $237(2.4)$ & $290(3.0)$ & $70(45.5)$ & $18(45.7)$ \\
\hline Healthcare specialists & $161(2.9)$ & $193(3.5)$ & $57(56.4)$ & $86(50.0)$ \\
\hline $\begin{array}{l}\text { Service supply and } \\
\text { functional }\end{array}$ & $432(3.1)$ & $529(3.8)$ & $153(46.2)$ & $41(43.8)$ \\
\hline
\end{tabular}

*Taken at time of baseline submission of questionnaire among members who submitted questionnaires at baseline (July 2001-June 2003) and followup (July 2004-Jan 2006).

†Self reported post-traumatic stress disorder symptoms based on posttraumatic stress disorder patient checklist-civilian version with DSM-IV criteria or diagnosis of post-traumatic stress disorder within previous three years.

$\ddagger$ Self reported post-traumatic stress disorder symptoms based on posttraumatic stress disorder patient checklist-civilian version with DSM-IV criteria and a sum of 50 points out of 85 points possible or diagnosis of post-traumatic stress disorder within previous three years.

§Deployment in support of wars in Iraq and Afghanistan considered if full deployment occurred between submission dates of baseline and follow-up questionnaires. Cohort members who were deployed after follow-up survey are included with non-deployers in these analyses. 
Tables 3 and 4 also present persistent self reported symptoms of post-traumatic stress disorder among cohort members with symptoms at baseline (995 on the basis of the specific criteria and 1659 on the basis of the sensitive criteria). We removed members with a self reported diagnosis of post-traumatic stress disorder at baseline but no current symptoms at baseline from these analyses. We found persistent self reported symptoms of post-traumatic stress disorder defined by the specific criteria in $43.5 \%$ of cohort members who were deployed to the wars in Iraq and Afghanistan and reported combat exposures, $26.2 \%$ of cohort members

Table 5 |Adjusted odds of new onset post-traumatic stress disorder*, stratified by US army and air force, among millennium cohort members without baseline post-traumatic stress disorder symptoms

\begin{tabular}{|c|c|c|c|c|}
\hline \multirow[b]{2}{*}{ Characteristic $\dagger$} & \multicolumn{2}{|c|}{ Army cohort members $(n=22959)$} & \multicolumn{2}{|c|}{ Air force cohort members $(n=14608)$} \\
\hline & Percentage & Odds ratio $(95 \% \mathrm{Cl})$ & Percentage & Odds ratio $(95 \% \mathrm{Cl})$ \\
\hline \multicolumn{5}{|l|}{ Deploymentł } \\
\hline Not deployed & 3.0 & 1.00 & 1.2 & 1.00 \\
\hline Deployed without combat exposures & 2.6 & $0.87(0.64$ to 1.18$)$ & 0.7 & $0.56(0.35$ to 0.89$)$ \\
\hline Deployed with combat exposures & 9.3 & 3.59 (3.08 to 4.17$)$ & 3.5 & 3.38 (2.29 to 4.98$)$ \\
\hline \multicolumn{5}{|l|}{ Sex } \\
\hline Male & 3.6 & 1.00 & 1.0 & 1.00 \\
\hline Female & 4.9 & $1.70(1.44$ to 2.00$)$ & 2.0 & $2.00(1.41$ to 2.83$)$ \\
\hline \multicolumn{5}{|l|}{ Birth year } \\
\hline Pre-1960 & 3.1 & 1.00 & 1.2 & 1.00 \\
\hline 1960-9 & 3.5 & $0.90(0.74$ to 1.10$)$ & 1.0 & $0.84(0.56$ to 1.24$)$ \\
\hline 1970-9 & 4.9 & 1.09 (0.88 to 1.36$)$ & 1.6 & $1.40(0.89$ to 2.21$)$ \\
\hline 1980 and forward & 6.0 & $1.17(0.83$ to 1.65$)$ & 2.5 & $1.72(0.70$ to 4.26$)$ \\
\hline \multicolumn{5}{|l|}{ Education } \\
\hline High school or less diploma/equivalent & 5.0 & 1.00 & 2.2 & 1.00 \\
\hline Some college or bachelor's degree & 2.8 & $0.83(0.69$ to 1.00$)$ & 1.2 & $0.75(0.50$ to 1.14$)$ \\
\hline Advanced degree & 1.9 & $0.80(0.54$ to 1.19$)$ & 0.6 & $0.82(0.35$ to 1.92$)$ \\
\hline \multicolumn{5}{|l|}{ Marital status } \\
\hline Married & 3.7 & 1.00 & 1.1 & 1.00 \\
\hline Never married & 4.4 & $0.80(0.67$ to 0.96$)$ & 1.3 & 0.79 (0.51 to 1.23$)$ \\
\hline Divorced & 4.7 & $1.09(0.85$ to 1.40$)$ & 2.7 & $1.85(1.25$ to 2.74$)$ \\
\hline \multicolumn{5}{|l|}{ Race/ethnicity } \\
\hline White non-Hispanic & 4.0 & 1.00 & 1.3 & 1.00 \\
\hline Black non-Hispanic & 4.5 & 1.14 (0.93 to 1.38$)$ & 1.2 & $0.86(0.51$ to 1.47$)$ \\
\hline Other & 3.5 & 1.37 (1.13 to 1.65$)$ & 1.4 & $1.06(0.63$ to 1.76$)$ \\
\hline \multicolumn{5}{|l|}{ Smoking } \\
\hline Never smoker & 3.2 & 1.00 & 1.1 & 1.00 \\
\hline Past smoker & 4.1 & 1.21 (1.03 to 1.44$)$ & 1.3 & 1.05 (0.73 to 1.50$)$ \\
\hline Current smoker & 6.4 & $1.69(1.42$ to 2.01$)$ & 2.1 & $1.40(0.94$ to 2.07$)$ \\
\hline \multicolumn{5}{|l|}{ Problem drinking } \\
\hline No & 3.6 & 1.00 & 1.2 & 1.00 \\
\hline Yes & 5.4 & $1.47(1.25$ to 1.73$)$ & 1.9 & $1.69(1.17$ to 2.43$)$ \\
\hline \multicolumn{5}{|l|}{ Military rank } \\
\hline Enlisted & 4.8 & 2.20 (1.70 to 2.86$)$ & 1.5 & $2.31(1.24$ to 4.30$)$ \\
\hline Officer & 1.9 & 1.00 & 0.6 & 1.00 \\
\hline \multicolumn{5}{|l|}{ Service component } \\
\hline Reserve/National Guard & 3.8 & 1.00 & 1.5 & 1.00 \\
\hline Active duty & 4.1 & 0.88 (0.76 to 1.03$)$ & 1.1 & $0.79(0.56$ to 1.13$)$ \\
\hline \multicolumn{5}{|l|}{ Occupational category } \\
\hline Other occupations & 4.4 & 1.00 & 1.3 & 1.00 \\
\hline Combat specialists & 3.3 & $0.91(0.75$ to 1.11$)$ & 0.7 & 0.71 (0.41 to 1.25$)$ \\
\hline Healthcare specialists & 3.7 & 1.02 (0.81 to 1.29$)$ & 1.3 & $0.78(0.46$ to 1.33$)$ \\
\hline Service supply and functional & 4.1 & 0.95 (0.80 to 1.12$)$ & 1.4 & $0.93(0.65$ to 1.33$)$ \\
\hline \multicolumn{5}{|c|}{$\begin{array}{l}\text { *Self reported post-traumatic stress disorder symptoms based on posttraumatic stress disorder patient checklist-civilian version with DSM-IV criteria } \\
\text { and a sum of } 50 \text { points out of } 85 \text { points possible or diagnosis of post-traumatic stress disorder within previous three years. } \\
\text { †Characteristic taken at time of submission of baseline questionnaire among members who submitted questionnaires at baseline (July 2001-June } \\
\text { 2003) and follow-up (July 2004-Jan 2006). } \\
\text { †Deployment in support of wars in Iraq and Afghanistan considered if full deployment occurred between submission dates of baseline and follow-up } \\
\text { questionnaires. Cohort members who were deployed after follow-up survey are included with non-deployers in these analyses. }\end{array}$} \\
\hline
\end{tabular}


who were deployed and did not report combat exposures, and $47.6 \%$ of non-deployed cohort members. Applying the more sensitive criteria alone, we identified persistent self reported symptoms of posttraumatic stress disorder in $47.9 \%, 22.4 \%$, and $45.9 \%$ of these groups. Persistent self reported symptoms were proportionately higher among older, higher educated, and divorced personnel; among officers, Reserve/ National Guard members, marines, and healthcare specialists; and in those who self reported being a smoker or problem drinker at baseline.

Using a variance inflation level of 4 , we found no demographic, behavioural, or military variables that exhibited multicollinearity. Tables 5 and 6 present

Table 6 | Adjusted odds of new onset post-traumatic stress disorder*, stratified byUSnavy/Coast Guard and Marine Corps, among millennium cohort members without baseline post-traumatic stress disorder symptoms

\begin{tabular}{|c|c|c|c|c|}
\hline \multirow[b]{2}{*}{ Characteristic $†$} & \multicolumn{2}{|c|}{ Navy and Coast Guard cohort members $(n=8655)$} & \multicolumn{2}{|c|}{ Marine cohort members $(n=2077)$} \\
\hline & Percentage & Odds ratio $(95 \% \mathrm{Cl})$ & Percentage & Odds ratio $(95 \% \mathrm{Cl})$ \\
\hline \multicolumn{5}{|l|}{ Deploymentł } \\
\hline Not deployed & 2.2 & 1.00 & 2.3 & 1.00 \\
\hline Deployed without combat exposures & 1.4 & $0.60(0.35$ to 1.02$)$ & 2.8 & $1.42(0.57$ to 3.51$)$ \\
\hline Deployed with combat exposures & 5.2 & $2.48(1.48$ to 4.14$)$ & 5.7 & $2.78(1.52$ to 5.07$)$ \\
\hline \multicolumn{5}{|l|}{ Sex } \\
\hline Male & 1.8 & 1.00 & 2.8 & 1.00 \\
\hline Female & 3.4 & $1.73(1.25$ to 2.38$)$ & 4.4 & $1.92(0.94$ to 3.94$)$ \\
\hline \multicolumn{5}{|l|}{ Birth year } \\
\hline Pre-1960 & 2.0 & 1.00 & 1.2 & 1.00 \\
\hline $1960-9$ & 2.1 & 0.99 (0.66 to 1.48$)$ & 1.4 & $0.71(0.18$ to 2.79$)$ \\
\hline $1970-9$ & 2.4 & $0.97(0.60$ to 1.56$)$ & 3.9 & $1.51(0.40$ to 5.70$)$ \\
\hline 1980 and forward & 5.2 & 1.73 (0.79 to 3.78$)$ & 6.8 & $2.00(0.42$ to 9.56$)$ \\
\hline \multicolumn{5}{|l|}{ Education } \\
\hline High school or less diploma/equivalent & 2.7 & 1.00 & 3.8 & 1.00 \\
\hline Some college or bachelor's degree & 1.6 & 0.89 (0.57 to 1.39$)$ & 1.4 & $0.70(0.22$ to 2.20$)$ \\
\hline Advanced degree & 1.6 & 1.31 (0.60 to 2.88$)$ & 0.7 & $0.57(0.05$ to 6.17$)$ \\
\hline \multicolumn{5}{|l|}{ Marital status } \\
\hline Married & 1.9 & 1.00 & 2.0 & 1.00 \\
\hline Never married & 2.7 & 1.14 (0.81 to 1.61$)$ & 4.3 & 1.09 (0.56 to 2.10$)$ \\
\hline Divorced & 4.9 & $2.53(1.31$ to 4.91$)$ & 5.7 & $2.75(1.06$ to 7.14$)$ \\
\hline \multicolumn{5}{|l|}{ Race/ethnicity } \\
\hline White non-Hispanic & 2.0 & 1.00 & 2.9 & 1.00 \\
\hline Black non-Hispanic & 3.5 & $1.54(1.02$ to 2.34$)$ & 1.6 & 0.70 (0.21 to 2.36$)$ \\
\hline Other & 2.6 & $1.22(0.80$ to 1.88$)$ & 4.3 & $1.53(0.78$ to 3.01$)$ \\
\hline \multicolumn{5}{|l|}{ Smoking } \\
\hline Never smoker & 1.8 & 1.00 & 2.1 & 1.00 \\
\hline Past smoker & 2.5 & 1.33 (0.94 to 1.88$)$ & 3.6 & 1.55 (0.83 to 2.88$)$ \\
\hline Current smoker & 3.4 & 1.59 (1.08 to 2.34$)$ & 5.7 & 1.84 (0.94 to 3.59$)$ \\
\hline \multicolumn{5}{|l|}{ Problem drinking } \\
\hline No & 2.0 & 1.00 & 2.4 & 1.00 \\
\hline Yes & 3.1 & 1.59 (1.08 to 2.34$)$ & 4.7 & 1.73 (1.00 to 2.99$)$ \\
\hline \multicolumn{5}{|l|}{ Military rank } \\
\hline Enlisted & 2.7 & 2.14 (1.16 to 3.94$)$ & 3.7 & $1.92(0.52$ to 7.13$)$ \\
\hline Officer & 1.3 & 1.00 & 1.1 & 1.00 \\
\hline \multicolumn{5}{|l|}{ Service component } \\
\hline Reserve/National Guard & 2.1 & 1.00 & 2.5 & 1.00 \\
\hline Active duty & 2.3 & 1.24 (0.86 to 1.77$)$ & 3.1 & $1.24(0.62$ to 2.47$)$ \\
\hline \multicolumn{5}{|l|}{ Occupational category } \\
\hline Other occupations & 2.0 & 1.00 & 2.8 & 1.00 \\
\hline Combat specialists & 1.7 & $1.14(0.72$ to 1.79$)$ & 3.7 & $1.63(0.86$ to 3.06$)$ \\
\hline Healthcare specialists & 3.1 & 1.49 (0.96 to 2.32$)$ & - & - \\
\hline Service supply and functional & 2.6 & 1.23 (0.85 to 1.79$)$ & 2.7 & $1.02(0.52$ to 1.99$)$ \\
\hline
\end{tabular}

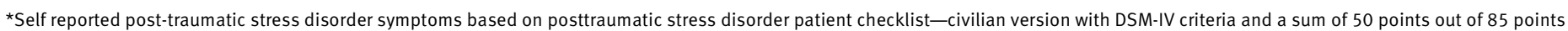
possible or diagnosis of post-traumatic stress disorder within previous 3 years.

†Taken at time of baseline questionnaire submission among members who submitted questionnaires at baseline (July 2001-June 2003) and follow-up (July 2004-Jan 2006).

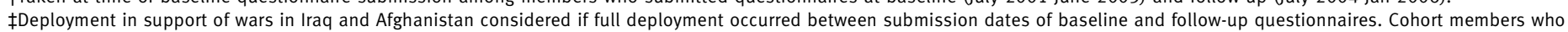
were deployed after follow-up survey are included with non-deployers in these analyses. 
logistic regression results for new onset self reported symptoms or diagnosis of post-traumatic stress disorder based on the more specific criteria, stratified by branch of service. Analyses included adjustment for baseline characteristics including sex, age, education, marital status, race/ethnicity, rank, service component, occupation, cigarette smoking, and problem alcohol drinking. Among all of the services, deployed personnel who reported combat exposures had significantly higher odds of post-deployment self reported posttraumatic stress disorder symptoms than did those who were not deployed (army odds ratio 3.59, 95\% confidence interval 3.08 to 4.17 ; air force odds ratio 3.38, 2.29 to 4.98; navy/Coast Guard odds ratio 2.48, 1.48 to 4.14 ; Marine Corps odds ratio 2.78, 1.52 to 5.07). Being female, divorced, or enlisted and reporting problem alcohol drinking were also associated with increased odds of new onset self reported symptoms or diagnosis in at least three of the four service branches. Among the air force members, deployers who did not report combat exposures had significantly lower odds of post-deployment self reported symptoms or diagnosis of post-traumatic stress disorder (odds ratio 0.56, 0.36 to 0.90$)$ than did non-deployers. We found no statistical difference between deployed army, navy/ Coast Guard, and Marine Corps cohort members who did not report combat exposures when compared with non-deployers.

\section{DISCUSSION}

In this study, we document an increased risk of new onset self reported symptoms of post-traumatic stress disorder among cohort members who were female, divorced, or enlisted, and in those who self reported being a current smoker or problem drinker at baseline. Furthermore, we report overall new incidence rates of 10-13 cases per 1000 person years and a threefold increase in new onset self reported symptoms of posttraumatic stress disorder in deployed personnel who reported combat exposures compared with nondeployers. The complexity and diversity of combat deployments and associated morbidity is a cause for much concern among veterans and the public about the health of military personnel returning from deployments to Iraq and Afghanistan. ${ }^{23-25}$ The unpredictability and intensity of urban combat, constant risk of roadside bombs, multiple and prolonged tours, and complex problems of differentiating enemies from allies can leave many troops with high stress levels and possible lasting health consequences. Millennium cohort study data allow a unique opportunity to observe new onset and persistent self reported symptoms of post-traumatic stress disorder in a large population based military cohort.

\section{Limitations and strengths}

Limitations to these analyses should be noted. The millennium cohort, by design, oversampled female, previously deployed, and Reserve/National Guard personnel and may not be representative of the military population in general or of all deployers. However, approximately $40 \%$ of the cohort were deployed in support of the wars in Iraq and Afghanistan between 2001 and 2006; 24\% were deployed for the first time between baseline and follow-up. Approximately 30\% of the US military on rosters when the cohort was established were deployed during the same period (data not shown). This indicates a robust cohort for investigating deployment related concerns.

The millennium cohort study was able to track and obtain a follow-up questionnaire from more than $70 \%$ of those who submitted a baseline questionnaire; however, response biases may exist. Although participants self selected in accepting the invitation to become part of the cohort, and investigation of possible biases in follow-up participants continues, reports of millennium cohort baseline data suggest a representative sample of military personnel measured by demographic and health characteristics and reliable health and exposure reporting. ${ }^{10-1626}$ Even so, assessment of exposure and outcomes through self report is challenging and represents an estimate of the true prevalence of exposures and disease. Studies have shown that increased reporting of exposure and symptoms occurs among personnel who seek medical compensation, ${ }^{27}$ as well as among those with symptoms of post-traumatic stress disorder. ${ }^{28}$ If the onset of symptoms in this cohort caused an increase in reporting of exposure, or if significant exposures caused an artificial increase in reporting of symptoms, the results of this study would overestimate the true burden of the disease. Furthermore, we categorised these data into deployment with and without combat on the basis of a set of five questions that may not truly indicate that a person specifically saw combat. This may in turn have biased these findings towards the null, and only true isolation of exposure and disease outcome would quantify the true effect. Compensation has not been offered to millennium cohort participants, which should reduce potential bias associated with compensation. Personnel may conceivably participate, however, and self report conditions and exposures likely to result in potential future healthcare benefits. More research into millennium cohort participants presenting for Veterans Administration care will help us to understand this potential reporting bias. Also, we could not discern those exposures that are unique to combat from those that might be encountered through other occupational or non-occupational activities. Furthermore, although these data have shown good reliability in test-retest analyses and strong internal consistency, ${ }^{11}$ self reported data in general have inherent limitations that may lead to information bias in these analyses.

Lastly, the use of a standardised instrument for self reported data along with no specific date of trauma as a surrogate for post-traumatic stress disorder diagnosis is imperfect. However, the posttraumatic stress disorder checklist - civilian version using the DSM-IV criteria along with a sum of 50 points has been found to correlate well with a physician's assessment of posttraumatic stress disorder symptoms,${ }^{17}$ and it is internally valid in millennium cohort members. ${ }^{11}$ 


\section{WHAT IS ALREADY KNOWN ON THIS TOPIC}

Post-traumatic stress disorder is associated with comorbidities and independently with military combat deployments

No published data describe the incidence of post-traumatic stress disorder or the persistence of symptoms in a large population based cohort

\section{WHAT THIS STUDY ADDS}

Female, divorced, or enlisted personnel and those who self reported being a current smoker or problem drinker at baseline had an increased risk of new onset self reported symptoms of posttraumatic stress disorder

Deployed personnel who reported combat exposures had a threefold increase in new onset self reported symptoms of post-traumatic stress disorder compared with non-deployers

Unique strengths of these analyses should also be considered. This study is the first large, population based, prospective analysis of new onset self reported symptoms of post-traumatic stress disorder after combat deployment. Self reported data offer information not accessible elsewhere. Furthermore, posttraumatic stress disorder is often under-reported in electronic healthcare databases among populations who do not readily present for care for mental disorders. ${ }^{29}$ The use of a standardised instrument allows for comparison with other populations, such as the general US population and other military populations.

\section{Implications}

Studies have estimated that as many as 30\% of Vietnam war veterans developed post-traumatic stress disorder at some point after the war; between $9 \%$ and $15 \%$ had the disorder by the end of the 1980s. ${ }^{4031}$ Among 1991 Gulf war veterans, as many as $10 \%$ were reported to have post-traumatic stress disorder symptoms years after returning from deployment. ${ }^{79}$ Although not all post-traumatic stress disorder is war related, trends of persistent symptoms of post-traumatic stress disorder in veterans suggest what may be expected after the current combat deployments in Iraq and Afghanistan. Early identification of personnel with symptoms of post-traumatic stress disorder may lead to a smaller burden of the disorder in the years to come if appropriate and timely treatments are provided. In this study, the prevalence of new onset self reported symptoms or diagnosis of post-traumatic stress disorder varied from $1 \%$ to $10 \%$ from baseline to followup.

Differences in the amount of self reported posttraumatic stress disorder in returning US military found in these analyses compared with past reports are likely to be due to variations in the populations studied, time periods between assessment, and prospective methods. ${ }^{1-32} \mathrm{We}$ used the millennium cohort to prospectively investigate new onset and persistent self reported symptoms of post-traumatic stress disorder by differentiating those with self reported symptoms at baseline. The average time between baseline and follow-up was nearly three years, whereas the average time between the end of first deployment and follow-up was just over one year. A recent study reported that compared with $11.8 \%$ of US army personnel reporting symptoms of post-traumatic stress disorder soon after combat deployment, $16.7 \%$ reported symptoms six months post-deployment. ${ }^{32}$ This difference was larger among Reserve army personnel, $12.7 \%$ of whom reported symptoms after the end of deployment compared with $24.5 \%$ reporting symptoms six months post-deployment. In addition to the populations studied and the time periods between assessments, differences between these results and the results from our study may be due to the ability to consider those with and without symptoms or diagnosis of posttraumatic stress disorder at baseline. Nearly half of those with symptoms at baseline reported symptoms at follow-up, which would have increased the burden of post-deployment post-traumatic stress disorder symptoms if reported in the aggregate. In a recent report, ${ }^{1}$ the authors found a pre-deployment prevalence of symptoms of post-traumatic stress disorder of 5-9\%, compared with the millennium cohort baseline prevalence of 2-4\%. The millennium cohort allowed us to investigate a large, population based sample of US military members, which differs in composition from those in specific combat units who are involved with combat operations on a daily basis. Future longitudinal investigation of the millennium cohort will yield information that may be more temporally comparable to studies of symptoms in Vietnam and 1991 Gulf war veterans, conducted many years after deployment.

Overall, the rate of new onset self reported symptoms of post-traumatic stress disorder in deployed personnel was $4.3 \%$, a rate that is nearly twice that seen in non-deployed personnel $(2.3 \%)$. A better comparison group than non-deployers, however, might be deployers without combat exposures. The new onset of as many as 87 cases of self reported symptoms of post-traumatic stress disorder per 1000 combat deployers, compared with 21 cases per 1000 non-combat deployers, suggests that up to $76 \%$ of new onset self reported symptoms or diagnosis of posttraumatic stress disorder may be attributed to combat exposures in deployers. This report documents a threefold adjusted increase in risk of new onset self reported symptoms of post-traumatic stress disorder among those who were deployed and who also report combat exposures compared with non-deployed cohort members. The increase in risk would be much larger if the comparison was with non-combat deployers, suggesting that deployment in itself may not lead to the onset of post-traumatic stress disorder symptoms but rather that exposures during deployment contribute to the onset of symptoms.

We found persistent self reported symptoms of posttraumatic stress disorder at follow-up in 40-50\% of the $2.4 \%$ of millennium cohort members who had symptoms at baseline. ${ }^{26}$ This implies resiliency or recovery among more than half of the population between baseline and follow-up. Even so, this underscores a considerable burden of persistent symptoms of posttraumatic stress disorder among those with baseline self 
reported symptoms and suggests that resolution of post-traumatic stress disorder may not be expected for many years. Interestingly, cohort members who were older, higher educated, officers, and marines were more likely to experience persisting symptoms at follow-up. This contrasts with the lower odds of new onset symptoms in these personnel. This may reflect subgroups of the population who are concerned about the perceived stigma often associated with posttraumatic stress disorder. These groups may be less likely to report new onset symptoms; however, once they accept the diagnosis, they may be more willing to report problems they are experiencing. As found with new onset self reported symptoms of post-traumatic stress disorder, personnel with persisting symptoms were more likely to be divorced, Reserve/National Guard members, or healthcare specialists and to have reported problem alcohol drinking and cigarette smoking at baseline.

These prospective data show a threefold statistically significant increase in new onset self reported symptoms or diagnosis of post-traumatic stress disorder among recently deployed military personnel who report combat exposures. Compared with nondeployed personnel, we found no significant difference in new onset self reported symptoms or diagnosis of post-traumatic stress disorder among deployers who did not report combat exposures. Although the overall prevalence of post-traumatic stress disorder in the military is not high, a substantial number of cases can be expected on the basis of the number of service members deployed and exposed to combat over time in the wars in Iraq and Afghanistan. The risk of posttraumatic stress disorder conferred by combat exposure may not be preventable, but subsets of this population may exist who are even more vulnerable or, conversely, who retain a certain level of resilience to combat exposure. Future research should include efforts to better understand the resiliency and vulnerability to symptoms of post-traumatic stress disorder among subpopulations of combat deployers. Different types of research are also needed to investigate development of better validated and standardised screening and diagnostic approaches for post-traumatic stress disorder; population based controlled clinical trials on treatment strategies; and evaluations of how increased awareness, improved access to care, or both can reduce morbidity. Continued longitudinal investigation of post-traumatic stress disorder in the millennium cohort will yield even greater insight into the temporal onset of symptoms, the persistence or recurrence of symptoms, and recovery from this disorder.

We are indebted to all millennium cohort study participants. We thank Scott L Seggerman and Greg D Boyd from the Management Information Division, Defense Manpower Data Center, Seaside, CA. We also thank Lacy Farnell, Isabel Jacobson, Cynthia Leard, Travis Leleu, Robert Reed, Steven Spiegel, Kari Welch, and James Whitmer from the Department of Defense Center for Deployment Health Research; Michelle Stoia, from the Naval Health Research Center, San Diego, CA; and Karl E Friedl and professionals at the US Army Medical Research and Material Command, especially those from the Military Operational Medicine Research Program, Fort Detrick,
MD. We appreciate the support of the Henry M Jackson Foundation for the Advancement of Military Medicine, Rockville, MD.

In addition to the authors, the Millennium Cohort Study Team includes Pau J Amoroso, Madigan Army Medical Center, Tacoma, WA; Edward J Boyko, Seattle Epidemiologic Research and Information Center, Department of Veterans Affairs Puget Sound Health Care System, Seattle, WA; Gary D Gackstetter and Tomoko I Hooper, Department of Preventive Medicine and Biometrics, Uniformed Services University of the Health Sciences, Bethesda, MD; Gregory C Gray, College of Public Health, University of Iowa, lowa City, IA; James R Riddle and Timothy S Wells, Air Force Research Laboratory, Wright-Patterson Air Force Base, $\mathrm{OH}$; and Besa Smith,

Department of Defense Center for Deployment Health Research at the Naval Health Research Center, San Diego, CA

Contributors: TCS, MAKR, DLW, DJS, JFS, and DKS were involved in study design and concept. TCS and MAKR were involved in acquisition of data. TCS, MAKR, DLW, DJS, JFS, and DKS were responsible for analysis and interpretation of data. TCS, MAKR, DLW, DJS, JFS, and DKS drafted the manuscript. TCS, MAKR, DLW, DJS, JFS, and DKS did the statistical analysis. TCS, MAKR, DLW, DJS, JFS, and DKS critically revised the manuscript and approved the final version. TCS is the guarantor

Funding: This represents Naval Health Research Center report 07-09, supported by the Department of Defense, under work unit No 60002 Funding sources did not play any other role. The views expressed in this article are those of the authors and do not reflect the official policy or position of the US Department of the Navy; US Department of the Army; US Department of the Air Force; US Department of Defense; US Department of Veterans Affairs; US Government; University of California, San Diego; or San Diego State University.

Competing interests: None declared

Ethical approval: This research has been conducted in compliance with all applicable federal regulations governing the protection of human subjects in research (Protocol NHRC.2000.007).

Provenance and peer review: Not commissioned; externally peer reviewed.

1 Hoge CW, Castro CA, Messer SC, McGurk D, Cotting DI, Koffman RL. Combat duty in Iraq and Afghanistan, mental health problems, and barriers to care. N Engl J Med 2004;351:13-22.

2 Hoge CW, Auchterlonie JL, Milliken CS. Mental health problems, use of mental health services, and attrition from military service after returning from deployment to Iraq or Afghanistan. JAMA 2006;295:1023-32.

3 Vasterling JJ, Proctor SP, Amoroso P, Kane R, Heeren T, White RF. Neuropsychological outcomes of Army personnel following deployment to the Iraq war. JAMA 2006;296:519-29.

4 Dohrenwend BP, Turner JB, Turse NA, Adams BG, Koenen KC, Marshall R. The psychological risks of Vietnam for U.S. veterans: a revisit with new data and methods. Science 2006;313:979-82.

5 Thompson WW, Gottesman, II, Zalewski C. Reconciling disparate prevalence rates of PTSD in large samples of US male Vietnam veterans and their controls. BMC Psychiatry 2006;6:19.

6 Kang HK, Hyams KC. Mental health care needs among recent war veterans. N Engl J Med 2005;352:1289.

7 Kang HK, Natelson BH, Mahan CM, Lee KY, Murphy FM. Post-traumatic stress disorder and chronic fatigue syndrome-like illness among Gulf War veterans: a population-based survey of 30,000 veterans. Am J Epidemiol 2003;157:141-8.

8 Engel C), Engel A, Campbell S, McFall M, Russo J, Katon W. Posttraumatic stress disorder symptoms and precombat sexual and physical abuse in Desert Storm veterans. J Nerv Ment Dis 1993;181:683-8.

9 Stretch RH, Marlowe DH, Wright KM, Bliese PD, Knudson KH, Hoover CH. Post-traumatic stress disorder symptoms among Gulf war veterans. Mil Med 1996;161:407-10.

10 Ryan MA, Smith TC, Smith B, Amoroso P, Boyko El, Gray GC, et al. Millennium cohort: enrollment begins a 21-year contribution to understanding the impact of military service. J Clin Epidemiol 2007;60:181-91.

11 Smith TC, Smith B, Jacobson IG, Corbeil TE, Ryan MA. Reliability of standard health assessment instruments in a large, populationbased cohort study. Ann Epidemiol 2007;17:271-84.

12 Smith B, Leard CA, Smith TC, Reed RJ, Ryan MA. Anthrax vaccination in the millennium cohort: validation and measures of health. Am J Prev Med 2007;32:347-53.

13 Leardmann CA, Smith B, Smith TC, Wells TS, Ryan MA. Smallpox vaccination: comparison of self-reported and electronic vaccine records in the millennium cohort study. Hum Vaccin 2007;3:245-51.

14 Smith TC, Jacobson IG, Smith B, Hooper TI, Ryan MA, Team FT. The occupational role of women in military service: validation of 
occupation and prevalence of exposures in the millennium cohor study. Int J Environ Health Res 2007;17:271-84.

15 Smith B, Wingard DL, Ryan MAK, Macera CA, Patterson TL, Slymen D]. US military deployment during 2001-2006: comparison of subjective and objective data sources in a large prospective health study. Ann Epidemiol 2007;17:976-82.

16 Smith B, Smith TC, Gray GC, Ryan MA. When epidemiology meets the internet: web-based surveys in the millennium cohort study. Am J Epidemiol 2007;166:1345-54.

17 Brewin CR. Systematic review of screening instruments for adults at risk of PTSD. J Trauma Stress 2005;18:53-62.

18 American Psychiatric Association. Diagnostic and statistical manual of mental disorders , 4th ed.Washington, DC: American Psychiatric Association, 1994

19 Weathers FW, Litz BT, Herman DS, Huska JA, Keane TM. The PTSD checklist (PCL): reliability, validity, and diagnostic utility. Annual Meeting of International Society for Traumatic Stress Studies, Octobe 1993, San Antonio, Texas.

20 Blanchard EB, Jones-Alexander J, Buckley TC, Forneris CA. Psychometric properties of the PTSD checklist (PCL). Behav Res Ther 1996;34:669-73.

21 Wright KM, Huffman AH, Adler AB, Castro CA. Psychological screening program overview. Mil Med 2002;167:853-61.

22 Ewing JA. Detecting alcoholism: the CAGE questionnaire. JAMA 1984;252:1905-7.

23 Jones E, Hodgins-Vermaas R, McCartney H, Everitt B, Beech C, Poynter D, et al. Post-combat syndromes from the Boer war to the Gulf war: a cluster analysis of their nature and attribution. BMJ 2002;324:321-4.

24 Jones E, Vermaas RH, McCartney H, Beech C, Palmer I, Hyams K, et al. Flashbacks and post-traumatic stress disorder: the genesis of a 20thcentury diagnosis. Br J Psychiatry 2003;182:158-63.
25 Hyams KC, Wignall FS, Roswell R. War syndromes and their evaluation: from the U.S. civil war to the Persian Gulf war. Ann Intern Med 1996;125:398-405.

26 Riddle JR, Smith TC, Smith B, Corbeil TE, Engel CC, Wells TS, et al. Millennium cohort: the 2001-2003 baseline prevalence of mental disorders in the U.S. military. J Clin Epidemiol 2007;60:192-201.

27 Frueh BC, Elhai JD, Grubaugh AL, Monnier J, Kashdan TB, Sauvageot JA, et al. Documented combat exposure of US veterans seeking treatment for combat-related post-traumatic stress disorder. Br J Psychiatry 2005;186:467-72.

28 Koenen KC, Stellman SD, Dohrenwend BP, Sommer JF Jr, Stellman JM. The consistency of combat exposure reporting and course of PTSD in Vietnam war veterans. J Trauma Stress 2007;20:3-13.

29 Magruder KM, Frueh BC, Knapp RG, Davis L, Hamner MB, Martin RH, et al. Prevalence of posttraumatic stress disorder in Veterans Affairs primary care clinics. Gen Hosp Psychiatry 2005;27:169-79.

30 Kulka RA, Schlenger WE, Fairbank JA, Hough RL, Jordan BK, Marmar CR, et al. Trauma and the Vietnam war generation: report of findings from the national Vietnam veterans readjustment study. New York: Brunner/Mazel, 1990.

31 Eisen SA, Griffith KH, Xian H, Scherrer JF, Fischer ID, Chantarujikapong S, et al. Lifetime and 12-month prevalence of psychiatric disorders in 8,169 male Vietnam war era veterans. Mil Med 2004;169:896-902.

32 Milliken CS, Auchterlonie JL, Hoge CW. Longitudinal assessment of mental health problems among active and reserve component soldiers returning from the Iraq war. JAMA 2007;298:2141-8.

Accepted: 25 November 2007 